MSC 90B35, 90C11

DOI: $10.14529 / \mathrm{mmp} 190301$

\title{
ON TIME SELECTION FOR TRACK POSSESSION ASSIGNMENT AT THE RAILWAY STATION
}

\author{
A.N. Ignatov ${ }^{1}, A . V$. Naumov $^{1}$ \\ ${ }^{1}$ Moscow Aviation Institute, Moscow, Russian Federation \\ E-mails: alexei.ignatov1@gmail.com, naumovav@mail.ru
}

\begin{abstract}
We consider the problem on track possession assignment at the railway station. The problem is to determine the time during which the train traffic is interrupted for repair works at several railway tracks. To this end, we use a traffic schedule of the station in order to solve the problem on searching for the time interval having the following two properties. First, during this time interval, all track sections that are necessary to be repaired are vacant simultaneously. Second, this time interval has the maximum length. In addition, we solve two problems to determine the time interval having length that is not less than the length of the specified time interval in the following two cases. First, the desired time interval has the minimum number of occupied track sections that are necessary to be repaired. Second, the desired time interval has the minimum number of delayed (transferred) passenger/freight trains going through the tracks that are necessary to be repaired. All problems are solved by methods of mixed integer linear programming.
\end{abstract}

Keywords: track possession; station; schedule; mixed integer linear programming.

\section{Introduction}

One of the aims of both European railways and JSC "Russian Railways" is to increase the number of transported cargoes and passengers. This leads to the problem on increase in the capacity of railway stations and hauls.

Most papers devoted to the improvement of the railway traffic are related to the optimization of the traffic at hauls. Among other publications, we note [1-5]. The paper [1] gives a detailed review of studies on scheduling and cargo traffic. The paper [2] considers the problem to construct a cyclical schedule such that a train of a certain destination leaves a certain station at the same time every cycle, for example, every half hour or every hour. In $[3,4]$, the problem of locomotive delivery and transportation plans is solved. In [5], the same problem is solved taking into account the random delay in the readiness of a train for departure.

At the same time, a station with increase in traffic volumes plays no less important role than hauls. Indeed, the low capacity of the station can level down the entire positive effect of increase in the capacity of hauls. However, note that optimization of traffic at the station receives less attention than incidents and traffic on hauls. Among other works, we note [6-8]. The paper [6] investigates the problem to determine the arrival/departure time of a freight train to the station and the arrival platform. A simulation model of railway station functioning is presented in [7]. The paper [8] sets and solves the problem to optimize traffic of shunting trains around the station. Note that the necessary repairs at the station can also lead to decrease in capacity. Therefore, there exists the problem on 
track possession. The problem is to determine the time during which the train traffic on the haul, individual railway tracks of the haul or the railway station is interrupted for the repair and construction works [9].

Researches on track possession assignment are carried out for railway hauls and can be divided into several groups. One part of researches is devoted to the problem of track possession assignment based on the forecast of the state (degradation) of the railway infrastructure, the repairs cost, and the rail traffic volume [10-12]. The other part is devoted to the issue of track possession assignment based on the current schedule [13-15]. The paper [13] considers the problem of assigning technical brigades to maintain tracks. To this end, the paper [13] takes into account possible delays both in the train schedule and in the execution of technical works during the vacant time, when the tracks are free from passenger/freight trains. The optimization criterion is to minimize both the nonfulfillment of the basic schedule and the time execution of all planned technical works. The paper [13] assumes that the time is discrete (the discretization interval is equal to 1 second). This assumption is necessary, since extremely heavy traffic leads to a huge number of optimized variables in the proposed model. At the same time, the obtained problem of mathematical programming is nonlinear. The paper [14] considers a single-track railway with sidings, for which the entire original schedule of freight trains is restructured taking into account the need to hold track possessions on some sections of the track. In this case, the possession time is interpreted as a pseudo-train and can be transferred in time. The paper [15] considers a general view on a railway network, in which track possession can be transferred in time and trains can be canceled, delayed, or departed along different routes. The optimization criterion is to minimize adjustments to the original schedule of passenger/freight trains. However, the approach of simultaneous scheduling of passenger/freight trains and track possession used by $[14,15]$ cannot be transferred to the station. Indeed, passenger/freight trains carry out shunting operations, and it is necessary to change the execution schedule of these operations, as well as the routes of shunting locomotives, the searching for which is the subject of an individual study [8].

At present paper, we investigate the problem on track possession assignment at the railway station. To this end, we use various criterions that correlate with criterions from [13-15]. Namely, we use the following items as criterions for assignment:

- time interval with maximum length during which all track sections to be repaired are vacant simultaneously,

- time interval with duration that is not less than the duration of the specified time interval in which the number of occupied track sections to be repaired is minimal,

- time interval with duration that is not less than the duration of the specified time interval in which the number of delayed (postponed) passenger/freight trains going through the track to be repaired is minimal.

All problems are solved using mixed integer linear programming methods. A meaningful example is considered.

\section{Notation and Basic Assumptions}

Consider an undirected graph of the railway station $G=<V, E>$, where $V$ is a set of vertices (switches, joints between rails and entry (exit) points of the station (station boundaries)) and $E$ is a set of edges (railway tracks) connecting these vertices. Let $D$ : 
$E \rightarrow \mathbb{R}_{+}$be a function that characterizes the length of edges, and $|E|=m$. Enumerate edges of the graph $G$ from 1 to $m$ and compose a new graph $G^{\prime}=<V^{\prime}, E^{\prime}>$ whose vertices $V^{\prime}$ are numbers of edges of the graph $G$, i.e. $V^{\prime}=\{1,2, \ldots, m\}$. The set of edges $E^{\prime}$ includes edges between vertices from the set $V^{\prime}$, if these vertices are adjacent edges in the graph $G$.

Let us determine the time $t$ (in seconds) from the beginning of the day. Suppose that we have the passenger trains schedule and shunting operations schedule. Also, suppose that we use, for example, an algorithm from [8] to obtain a priori information on traffic of the shunting locomotives that perform these shunting operations. In this case, we can a priori specify the function $F_{\text {total }}: V^{\prime} \times \mathbb{R}_{+}^{1} \rightarrow\{0,1\}$ that characterizes the freeness of any edge of the graph $G$ from the traffic at the instant time $t$ :

$$
F_{\text {total }}(j, t) \stackrel{\text { def }}{=} \begin{cases}0, & \text { if the } \mathrm{j} \text {-th edge (of the graph } G) \\ 1, & \text { otherwise. }\end{cases}
$$

Let the station be crossed by $P$ passenger/freight trains during the day under consideration. Enumerate the trains in order of arrival at the station. For each of the trains, we can a priori set the function $F_{p}: V^{\prime} \times \mathbb{R}_{+}^{1} \rightarrow\{0,1\}$ that characterizes occupation of any edge of the graph $G$ by $p$-th train at the instant time $t$ :

$$
F_{p}(j, t) \stackrel{\text { def }}{=} \begin{cases}0, & \text { if the j-th edge (of the graph } G \text { ) } \\ 1, & \text { otherwise. }\end{cases}
$$

Note that

$$
\forall j \in V^{\prime} \forall t \sum_{p=1}^{P} F_{p}(j, t) \leq F_{\text {total }}(j, t) .
$$

\section{Problem Statement and Solution to the Problem}

Consider the problem on track possession assignment. The problem is to determine the time interval during which a certain set of edges $J=\left\{j_{1}, \ldots, j_{k}, \ldots, j_{K}\right\}$, where $j_{k} \in V^{\prime}$, is closed for traffic to provide technological works.

\subsection{Searching for Time Interval with Maximum Length During Which All Track Sections to Be Repaired Are Vacant Simultaneously}

At the beginning, we consider the case of searching for the time interval $\left(t_{1}^{*}, t_{2}^{*}\right)$ with maximum length $\Delta_{\max } \stackrel{\text { def }}{=} t_{2}^{*}-t_{1}^{*}$ during which all track sections (edges) included in the set $J$ are free from the traffic. In this case, the condition

$$
F_{\text {total }}\left(j_{k}, t\right)=0 \quad \forall t \in\left(t_{1}^{*}, t_{2}^{*}\right)
$$

must be satisfied $\forall j_{k} \in J$. This condition can be rewritten as

$$
\int_{t_{1}^{*}}^{t_{2}^{*}} F_{\text {total }}\left(j_{k}, t\right) d t=0
$$

The problem on searching for the desired interval is

$$
t_{2}-t_{1} \rightarrow \max _{t_{1}, t_{2}}
$$


with respect to

$$
\begin{gathered}
\forall j_{k} \in J \quad \int_{t_{1}}^{t_{2}} F_{\text {total }}\left(j_{k}, t\right) d t=0, \\
0 \leq t_{1} \leq t_{2} \leq 86400 \text { seconds, }
\end{gathered}
$$

where 86400 is the number of seconds in day.

Note that solution to problem (1) with respect to (2) - (3) may not exist. This case is possible, when there is no time interval in which all edges are simultaneously vacant. If the solution to problem (1) with respect to $(2)-(3)$ exists, then $t_{1}^{*}$ and $t_{2}^{*}$ are determined as the solution to this problem. However, problem (1) with respect to $(2)-(3)$ is nonlinear programming problem. Therefore, there is complexity in obtaining solution. We introduce integer variables in order to reduce this problem to the mixed integer programming problem.

To this end, we use the function $F_{\text {total }}(j, t)$ in order to form the set $\mathcal{T}_{k}$ consisted of the left and right boundaries of time intervals during which the $j_{k}$-th edge is free from the traffic, $k=\overline{1, K}$.

With the help of the set $\mathcal{T}_{k}$, we can determine the time intervals in which $j_{k}$-th edge is vacant. Arrange elements of the set $\mathcal{T}_{k}$ in ascending order and form the vector $\tau_{k}$. Suppose that

$$
\operatorname{dim} \tau_{k}=2 I_{k}
$$

where $I_{k}$ is the number of such intervals.

Introduce the new variable $\delta_{k}^{i}$ that is equal to 1 , if the time interval $\left[t_{1}, t_{2}\right]$ is entirely inside $\left[\tau_{k}^{2 i-1}, \tau_{k}^{2 i}\right]$ for the $j_{k}$-th edge, and is equal to 0 otherwise, $k=\overline{1, K}, i=\overline{1, I_{k}}$. In terms of the new variables $\delta_{k}^{i}$, problem (1) with respect to (2)-(3) is reduced to the problem

$$
t_{2}-t_{1} \rightarrow \max _{t_{1}, t_{2}, \delta_{1}^{1}, \ldots, \delta_{1}^{I_{1}}, \ldots, \delta_{K}^{1}, \ldots, \delta_{K}^{I_{K}}}
$$

with respect to

$$
\begin{gathered}
\sum_{i=1}^{I_{k}} \delta_{k}^{i}=1, k=\overline{1, K}, \\
t_{2} \leq \delta_{k}^{i} \tau_{k}^{2 i}+\left(1-\delta_{k}^{i}\right) 86400, k=\overline{1, K}, i=\overline{1, I_{k}}, \\
t_{1} \geq \delta_{k}^{i} \tau_{k}^{2 i-1}, k=\overline{1, K}, i=\overline{1, I_{k}}, \\
\delta_{k}^{i} \in\{0,1\}, k=\overline{1, K}, i=\overline{1, I_{k}}, \\
t_{1} \leq t_{2} .
\end{gathered}
$$

For each edge included in the set $J$, conditions $(5)-(7)$ guarantee that the time interval $\left(t_{1}, t_{2}\right)$ is entirely inside one of the time intervals, when this edge is free from the traffic. At the same time, upper and lower bounds of track possession does not exceed bounds of the day under consideration.

\subsection{Searching for Time Interval with Duration That Is Not Less Than the Specified One in Which the Number of Occupied Track Sections to Be Repaired Is Minimal}

As a rule, either the time interval $\left(t_{1}^{*}, t_{2}^{*}\right)$ is insufficient in terms of its length or the track possession should be assigned at the time in which edges from the set $J$ are occupied. Therefore, in order to assign track possession, it is necessary to transfer the traffic to other 
tracks (edges). To this end, consider the problem of searching for the time interval $\left(\hat{t}_{1}^{*}, \hat{t}_{2}^{*}\right)$ with duration that is not less than $\Delta$ in which the traffic has the minimal intensity. Here by intensity we understand the total (for all edges) number of time intervals when these edges are occupied inside suggested track possession.

If some subset of edges from the set $J$ is free from the traffic in the day under consideration, then remove this subset from the set $J$ and form the new set $\hat{J}$. Suppose that this set contains $\hat{K}$ edges and $\hat{J}=\left\{j_{(1)}, \ldots, j_{(k)}, \ldots, j_{(\hat{K})}\right\}$.

We use the function $F_{\text {total }}(j, t)$ in order to form the set $\hat{\mathcal{T}}_{k}$ consisted of the left and right boundaries of the time intervals in which the $j_{(k)}$-th edge is occupied by trains, $k=\overline{1, \hat{K}}$. With the help of the set $\hat{\mathcal{T}}_{k}$, we can determine the time intervals in which the $j_{(k)}$-th edge is occupied. Arrange elements of the set $\hat{\mathcal{T}}_{k}$ in ascending order and form the vector $\hat{\tau}_{k}$. Suppose that

$$
\operatorname{dim} \hat{\tau}_{k}=2 \hat{I}_{k}
$$

where $\hat{I}_{k}$ is the number of the time intervals, where the $j_{(k)}$-th edge is occupied.

Introduce the new variable $\hat{\delta}_{k}^{i}$ that is equal to 0 , if the intersection of the time interval $\left[t_{1}, t_{2}\right]$ with the interval $\left[\hat{\tau}_{k}^{2 i-1}, \hat{\tau}_{k}^{2 i}\right]$ consists of the single point as maximum, and is equal to 1 otherwise, $k=\overline{1, \hat{K}}, i=\overline{1, I_{k}}$. If the variable $\hat{\delta}_{k}^{i}$ is equal to 1 , then it is necessary to transfer the traffic from the $j_{(k)}$-th edge at the interval $\left[\hat{\tau}_{k}^{2 i-1}, \hat{\tau}_{k}^{2 i}\right]$ in the suggested track possession. If the variable $\hat{\delta}_{k}^{i}$ is equal to 0 , then either $t_{1} \geq \hat{\tau}_{k}^{2 i}$ or $t_{2} \leq \hat{\tau}_{k}^{2 i-1}$. Therefore, we introduce the auxiliary variables $\gamma_{k}^{i}, x_{k}^{i}$. The variable $\gamma_{k}^{i}$ is equal to 0 , if $t_{1} \geq \hat{\tau}_{k}^{2 i}$, and is equal to 1 otherwise. The variable $x_{k}^{i}$ is equal to 0 , if $t_{2} \leq \hat{\tau}_{k}^{2 i-1}$, and is equal to 1 otherwise. Note that the variable $\hat{\delta}_{k}^{i}$ is equal to 1 , only if $\gamma_{k}^{i}=\mathfrak{x}_{k}^{i}=1$. In terms of the variables $\gamma_{k}^{i}, æ_{k}^{i}$, we obtain the following form of the problem on searching for time interval with duration that is not less than the specified one in which the number of occupied track sections to be repaired is minimal:

$$
\begin{gathered}
\sum_{k=1}^{\hat{K}} \sum_{i=1}^{\hat{I}_{K}} \hat{\delta}_{k}^{i} \rightarrow \min _{t_{1}, t_{2}, \hat{\delta}_{k}^{i}, \gamma_{k}^{i}, æ_{k}^{i}, k=\overline{1, \hat{K}}, i=\overline{1, \hat{I}_{k}}} \\
t_{2}-t_{1} \geq \Delta, \\
t_{1} \geq\left(1-\gamma_{k}^{i}\right) \hat{\tau}_{k}^{2 i}, k=\overline{1, \hat{K}}, i=\overline{1, \hat{I}_{k}}, \\
t_{2} \leq\left(1-æ_{k}^{i}\right) \hat{\tau}_{k}^{2 i-1}+86400 æ_{k}^{i}, k=\overline{1, \hat{K}}, i=\overline{1, \hat{I}_{k}}, \\
\hat{\delta}_{k}^{i} \geq \gamma_{k}^{i}+æ_{k}^{i}-1, k=\overline{1, \hat{K}}, i=\overline{1, \hat{I}_{k}}, \\
\hat{\delta}_{k}^{i} \in\{0,1\}, \gamma_{k}^{i} \in\{0,1\}, æ_{k}^{i} \in\{0,1\}, k=\overline{1, \hat{K}}, i=\overline{1, \hat{I}_{k}} .
\end{gathered}
$$

Condition (11) guarantees that the length of the obtained time interval is not less than the preset parameter $\Delta$. Conditions (12) - (13) are necessary to verify that the conditions $t_{1} \geq \hat{\tau}_{k}^{2 i}$ and $t_{2} \leq \hat{\tau}_{k}^{2 i-1}$ are fulfilled. Taking into account conditions (15) and the form of the function to be optimized, we obtain that condition (14) guarantees that $\hat{\delta}_{k}^{i}$ is equal to 0 , if either $x_{k}^{i}$ or $\gamma_{k}^{i}$ is equal to 0 . If both these variables are equal to 1 , then $\hat{\delta}_{k}^{i}$ is equal to 1 .

Note that, in contrast to problem (4) with respect to (5) - (9), problem (10) with respect to (11) - (15) always has solutions. Also, problem (4) with respect to (5) - (9) and problem (10) with respect to (11) - (15) are inverse in some sense. In the first problem, the time interval is searched with the strict restriction that every considered edge must 
be vacant. In the second problem, the length of the interval is bounded, and some edges can be occupied inside this interval. At the same time, the solution to problem (10) with respect to $(11)-(15)$ is meaningful only when $\Delta_{\max }<\Delta$.

Note that problem (10) with respect to (11) - (15) can have several solutions. Therefore, from all solutions to this problem, we choose the best solution in terms of maximum length of the time interval in which we need to transfer the traffic from edges that belong to the set $J$ only $\hat{f}^{*}$ times, where $\hat{f}^{*}$ is an optimal value of the criterion in problem (10) with respect to (11) - (15). Therefore, the potential track possession can be increased, and there is no additional transfer of the traffic.

To this end, we need to solve the problem

$$
t_{2}-t_{1} \rightarrow \max _{t_{1}, t_{2}, \hat{\delta}_{k}^{i}, \gamma_{k}^{i}, \circledast_{k}^{i}, k=\overline{1, \hat{K}, i=\overline{1, \hat{I}_{k}}}}
$$

with respect to (11)-(15) and the additional condition

$$
\sum_{k=1}^{\hat{K}} \sum_{i=1}^{\hat{I}_{K}} \hat{\delta}_{k}^{i}=\hat{f}^{*} .
$$

Therefore, we have the solution to problem (16) with respect to (11) - (15), (17) and can set the desired $\hat{t}_{1}^{*}$ and $\hat{t}_{2}^{*}$.

\subsection{Searching for Time Interval with Duration That Is Not Less Than Specified One in Which Number of Delayed (Postponed) Passenger/Freight Trains Going Through Track to Be Repaired Is Minimal}

There can be another sense of traffic intensity. The intensity can be understood as the number of passenger/freight trains to be either transferred to neighboring free routes or simply accepted later due to track possession assignment. In this regard, we consider the problem of searching for the time interval $\left(\tilde{t}_{1}^{*}, \tilde{t}_{2}^{*}\right)$ with duration that is not less than $\Delta$ in which the preassigned set of edges $J=\left\{j_{1}, \ldots, j_{k}, \ldots, j_{K}\right\}$, where $j_{k} \in V^{\prime}$ is occupied by the minimum number of passenger/freight trains. If trains do not occupy some edges from the set $J$, we exclude these edges from consideration and renumber the remaining edges according to the order of arrival at the station. Suppose that $\tilde{P} \geq 1$ trains remain after such exclusion. Introduce the new variable $\tilde{\delta}_{p}$ that is equal to 0 , if the $p$-th passenger/freight train is not transferred or delayed, and is equal to 1 otherwise. For the $p$-th train we consider only such edges from the traffic route at the station that belong to the set $J$, and exclude from consideration the remaining edges. Suppose that, after exclusion of such edges, $\tilde{K}_{p}$ items remain. Compose the new set $\tilde{J}_{p}=\left\{j_{(1)}^{p}, \ldots, j_{(k)}^{p}, \ldots, j_{\left(\tilde{K}_{p}\right)}^{p}\right\}$ from the remaining edges. For each edge that belongs to $\tilde{J}_{p}$, we use the function $F_{p}(j, t)$ in order to form the set $\tilde{\mathcal{T}}_{p, k}$ consisted of the left and right boundaries of the time intervals when the $j_{(k)}^{p}$-th edge is occupied by the $p$-th train, $p=\overline{1, \tilde{P}}, k=\overline{1, \tilde{K}_{p}}$. With the help of the set $\tilde{\mathcal{T}}_{p, k}$, we can determine time intervals in which the $j_{(k)}$-th edge is occupied by the $p$-th train. Arrange elements of the set $\tilde{\mathcal{T}}_{p, k}$ in ascending order and form the vector $\tilde{\tau}_{p, k}$. Suppose that

$$
\operatorname{dim} \tilde{\tau}_{p, k}=2 \tilde{I}_{p, k}
$$

where $\tilde{I}_{p, k}$ is the number of such intervals. 
Introduce the new variable $\tilde{\delta}_{p, k}^{i}$ that is equal to 0 , if the intersection of the time interval $\left[t_{1}, t_{2}\right]$ with the interval $\left[\tilde{\tau}_{p, k}^{2 i-1}, \tilde{\tau}_{p, k}^{2 i}\right]$ consists of the single point as maximum, and is equal to 1 otherwise, $p=\overline{1, \tilde{P}}, k=\overline{1, \tilde{K}_{p}}, i=\overline{1, \tilde{I}_{p, k}}$. If the variable $\tilde{\delta}_{p, k}^{i}$ is equal to 1 , then the $p$-th train should be transferred or delayed. The variable $\tilde{\delta}_{p, k}^{i}$ is equal to 0 , if either $t_{1} \geq \tilde{\tau}_{p, k}^{2 i}$ or $t_{2} \leq \tilde{\tau}_{p, k}^{2 i-1}$. Therefore, we introduce the additional variables $\gamma_{p, k}^{i}, æ_{p, k}^{i}$. The variable $\gamma_{p, k}^{i}$ is equal to 0 , if $t_{1} \geq \tilde{\tau}_{p, k}^{2 i}$, and is equal to 1 otherwise. The variable $æ_{p, k}^{i}$ is equal to 0 , if $t_{2} \leq \tilde{\tau}_{p, k}^{2 i-1}$, and is equal to 1 otherwise. Note that the variable $\hat{\delta}_{p, k}^{i}$ is equal to 1 , only if $\gamma_{k, p}^{i}=æ_{k, p}^{i}=1$. In terms of the introduced variables, we obtain the following form of the problem on searching for the time interval $\left(\tilde{t}_{1}^{*}, \tilde{t}_{2}^{*}\right)$ with duration that is not less than $\Delta$ in which the preassigned set of edges $J=\left\{j_{1}, \ldots, j_{k}, \ldots, j_{K}\right\}$, where $j_{k} \in V^{\prime}$ is occupied with the minimal number of passenger/freight trains:

$$
\begin{aligned}
& \sum_{p=1}^{\tilde{P}} \tilde{\delta}_{p} \rightarrow \min _{t_{1}, t_{2}, \tilde{\delta}_{p}, \tilde{\delta}_{p, k}^{i}, \gamma_{p, k}^{i}, \circledast_{p, k}^{i}, p=\overline{1, \tilde{P}}, k=\overline{1, \tilde{K}_{p}}, i=\overline{1, \tilde{I}_{p, k}}} \\
& t_{2}-t_{1} \geq \Delta \\
& t_{1} \geq\left(1-\gamma_{p, k}^{i}\right) \tilde{\tau}_{p, k}^{2 i}, p=\overline{1, \tilde{P}}, k=\overline{1, \tilde{K}_{p}}, i=\overline{1, \tilde{I}_{p, k}}, \\
& t_{2} \leq\left(1-æ_{p, k}^{i}\right) \tilde{\tau}_{p, k}^{2 i-1}+86400 æ_{p, k}^{i}, p=\overline{1, \tilde{P}}, k=\overline{1, \tilde{K}_{p}}, i=\overline{1, \tilde{I}_{p, k}}, \\
& \tilde{\delta}_{p, k}^{i} \geq \gamma_{p, k}^{i}+x_{p, k}^{i}-1, p=\overline{1, \tilde{P}}, k=\overline{1, \tilde{K}_{p}}, i=\overline{1, \tilde{I}_{p, k}} \\
& \tilde{\delta}_{p} \geq \frac{\sum_{k=1}^{\tilde{K}_{p}} \sum_{i=1}^{\tilde{I}_{p, k}} \tilde{\delta}_{p, k}^{i}}{\sum_{k=1}^{\tilde{K}_{p}} \tilde{I}_{p, k}}, p=\overline{1, \tilde{P}}, \\
& \tilde{\delta}_{p} \in\{0,1\}, \tilde{\delta}_{p, k}^{i} \in\{0,1\}, \gamma_{p, k}^{i} \in\{0,1\}, æ_{p, k}^{i} \in\{0,1\}, p=\overline{1, \tilde{P}}, k=\overline{1, \tilde{K}_{p}}, i=\overline{1, \tilde{I}_{p, k}}
\end{aligned}
$$

Conditions (23) are the main conditions in problem (18) with respect to (19) - (24). These conditions are necessary in order to determine whether the $p$-th train should be transferred. First of all, note that

$$
0 \leq \sum_{k=1}^{\tilde{K}_{p}} \sum_{i=1}^{\tilde{I}_{p, k}} \tilde{\delta}_{p, k}^{i} \leq \sum_{k=1}^{\tilde{K}_{p}} \tilde{I}_{p, k} .
$$

At the same time, if at least one edge included in the set of edges $J$ from the route of a passenger/freight train is occupied at the time interval $\left(t_{1}, t_{2}\right)$, then at least one variable $\tilde{\delta}_{p, k}^{i}$ is equal to 1 . Consequently,

$$
\tilde{\delta}_{p} \geq \frac{\sum_{k=1}^{\tilde{K}_{p}} \sum_{i=1}^{\tilde{I}_{p, k}} \tilde{\delta}_{p, k}^{i}}{\sum_{k=1}^{\tilde{K}_{p}} \tilde{I}_{p, k}}>0 .
$$

Therefore, taking into account conditions (24), we have that $\tilde{\delta}_{p}=1$. Conditions $(20)-(22)$ are similar to conditions $(12)-(14)$ with only difference that conditions $(20)-(22)$ point to freeness or occupation by individual train at the time interval $\left(t_{1}, t_{2}\right)$, while conditions $(12)$ - (14) point to freeness or occupation by all trains going through the station at the time interval $\left(t_{1}, t_{2}\right)$.

Note that problem (18) with respect to (19) - (24) can have several solutions. Therefore, from all solutions to this problem, we choose the best solution in terms of 
maximum length of the time interval at which we need to change the route only for $\tilde{f}^{*}$ trains, where $\tilde{f}^{*}$ is an optimal value of the criterion in problem (18) with respect to (19) - (24). To this end, we need to solve the problem

$$
t_{2}-t_{1} \rightarrow \max _{t_{1}, t_{2}, \tilde{\delta}_{p}, \tilde{\delta}_{p, k}^{i}, \gamma_{p, k}^{i}, \circledast_{p, k}^{i}, p=\overline{1, \tilde{P}}, k=\overline{1, \tilde{K}_{p}, i=1, \tilde{I}_{p, k}}}
$$

with respect to $(19)-(24)$ and the additional condition

$$
\sum_{p=1}^{\tilde{P}} \tilde{\delta}_{p}=\tilde{f}^{*} .
$$

Therefore, we have the solution to problem (25) with respect to (19) - (24), (26) and can set the desired $\tilde{t}_{1}^{*}$ and $\tilde{t}_{2}^{*}$.

\section{Example}

Consider some set of edges to be closed for the repair at the station with the part given in Figure. Suppose that these edges are occupied according to Table 1.

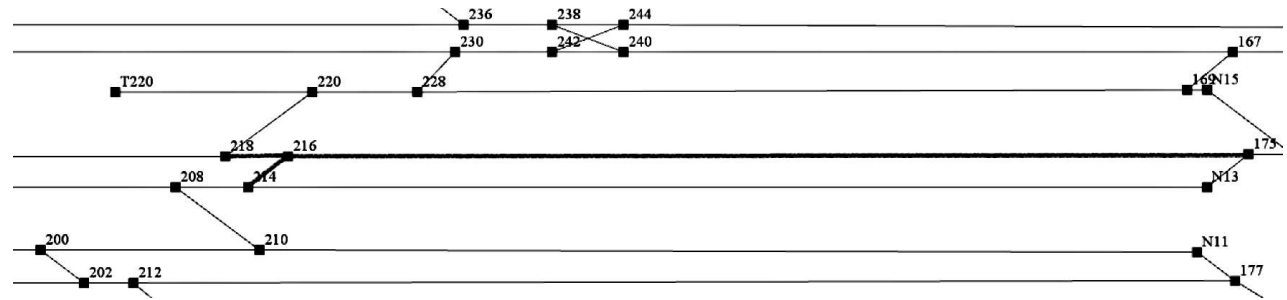

Scheme of the part of the station with track sections (edges) to be repaired marked by bold font

Table 1

Edges occupation time by trains

\begin{tabular}{|c|c|c|c|c|c|c|}
\hline \multirow{3}{*}{ Edge } & \multicolumn{7}{|c|}{ Occupation edge } \\
\cline { 2 - 8 } & From-till & No. & From-till & No. & From-till & No. \\
\hline \multirow{5}{*}{$216 \leftrightarrow 218$} & $2283-2327$ & 331 & $19743-19787$ & 59 & $25503-25547$ & 455 \\
\cline { 2 - 8 } & $30339-30778$ & & $33360-33389$ & & $34224-34266$ & 360 \\
\cline { 2 - 8 } & $34328-34357$ & & $37884-37926$ & 478 & $41314-41343$ & \\
\cline { 2 - 8 } & $43983-44027$ & 399 & $50004-50046$ & 130 & $55973-56015$ & 241 \\
\cline { 2 - 8 } & $66783-66827$ & 87 & $72783-72827$ & 97 & $81293-81322$ & \\
\cline { 2 - 8 } & $81352-81381$ & & \multicolumn{5}{|c|}{} & \\
\hline \multirow{5}{*}{$214 \leftrightarrow 216$} & $30088-30127$ & 122 & $31021-31049$ & & $33333-33360$ & \\
\cline { 2 - 8 } & $34300-34328$ & & $34950-34977$ & & $35221-35248$ & \\
\cline { 2 - 8 } & $41287-41314$ & & $41387-41414$ & & $48259-50698$ & \\
\cline { 2 - 8 } & $50941-50969$ & & $68053-70978$ & & $71221-71249$ & \\
\cline { 2 - 8 } & $74564-74591$ & & $75412-75439$ & & $83775-83802$ & \\
\cline { 2 - 8 } & $83-2283$ & 331 & $16343-19743$ & 59 & $22858-22979$ & \\
\cline { 2 - 8 } & $22980-25503$ & 455 & $30127-33639$ & 122 & $34266-36939$ & 360 \\
\cline { 2 - 8 } & $37926-40500$ & 478 & $41414-41658$ & & $41783-43983$ & 399 \\
\cline { 2 - 7 } & $50046-52599$ & 130 & $53663-55973$ & 241 & $63983-66783$ & 87 \\
\cline { 2 - 7 } & $68480-72783$ & 97 & $74591-74835$ & & $75168-75412$ & \\
\cline { 2 - 7 } & $81049-81293$ & & $81381-83268$ & & $83531-83775$ & \\
\hline
\end{tabular}


In Table 1, the column "No." gives the number of the passenger/freight train that occupy the edge pointed in the column "Edge" at the time interval given in the column "From-till". If a row in the column "No." is empty, then the edge is not occupied by a passenger/freight train, but, for example, is occupied by a shunting locomotive.

Taking into account the data shown in Table 1, we have that the solution to problem (4) with respect to conditions (5) - (9) is $t_{1}^{*}=2327$ and $t_{2}^{*}=16343$.

Now we analyze solutions to other stated problems depending on parameter $\Delta$.

It follows from Table 2 that the optimal time intervals generated by problem (16) with respect to (11) - (15), (17) and problem (25) with respect to (19) - (24), (26) can be different, but also can overlap. In this case, we expect that increase in the parameter $\Delta$ leads to increase in the optimal values of the corresponding criterial functions.

Table 2

Optimal time intervals

for track possession assignment

\begin{tabular}{|c|c|c|c|c|}
\hline$\Delta$ & $\hat{f}^{*}$ & $\left(\hat{t}_{1}^{*}, \hat{t}_{2}^{*}\right)$ & $\tilde{f}^{*}$ & $\left(\tilde{t}_{1}^{*}, \tilde{t}_{2}^{*}\right)$ \\
\hline 18000 & 2 & $(2327,22858)$ & 1 & $(2327,22980)$ \\
\hline 21600 & 4 & $(2327,25503)$ & 2 & $(56015,86400)$ \\
\hline 36000 & 16 & $(44027,81049)$ & 4 & $(44027,86400)$ \\
\hline 43200 & 24 & $(41658,86400)$ & 5 & $(40500,86400)$ \\
\hline
\end{tabular}

\section{Conclusion}

We investigate the problem on track possession assignment at the station taking into account the current schedule. In order to assign track possession, we consider different problems and solve the problems by methods of mixed integer linear programming. First, we solve the problem on searching for the time interval with maximum length during which all track sections to be repaired are vacant simultaneously. If the duration of such interval is insufficient, then we propose and solve the problem on searching for the time interval with duration that is not less than a predetermined one in which the number of occupied track sections to be repaired is minimal. If there is detailed information on trains going through track sections to be repaired, then in order to assign track possession, we solve the problem of searching for the time interval with duration that is not less than the specified one at which the number of delayed (transferred) passenger/freight trains going through track sections to be repaired is minimal.

Acknowledgements. This paper was performed in a framework of government assignment of the Ministry of Education and Science (project no. 2.2461.2017/Pch).

\section{References}

1. Cordeau J.-F., Toth P., Vigo D. A Survey of Optimization Models for Train Routing and Scheduling. Transportation Science, 1998, vol. 32, no. 4, pp. 380-404. DOI: $10.1287 / \operatorname{trsc} .32 .4 .380$

2. Peeters L.W.P. Cyclic Railway Timetable Optimization. PhD Thesis. 2003, Rotterdam.

3. Azanov V.M., Buyanov M.V., Gaynanov D.N., Ivanov S.V. Algorithm and Software Development to Allocate Locomotives for Transportation of Freight Trains. Bulletin of the South Ural State University. Series: Mathematical Modelling, Programming and Computer Software, 2016, vol. 9, no. 4, pp. 73-85. DOI: 10.14529/mmp160407 
4. Buyanov M.V., Kibzun A.I. Algorithm of Effective Transportation Work for Cargo Traffic. Bulletin of the South Ural State University. Series: Mathematical Modelling, Programming and Computer Software, 2018, vol. 11, no. 1, pp. 75-83. DOI: 10.14529/mmp180117

5. Buyanov M.V., Ivanov S.V., Kibzun A.I., Naumov A.V. Development of the Mathematical Model of Cargo Transportation Control on a Railway Network Segment Taking into Account Random Factors. Informatics and Applications, 2017, vol. 11, no. 4, pp. 85-93. DOI: $10.14357 / 19922264170411$ (in Russian)

6. Cacchiani V., Galli L., Toth P. A Tutorial on Non-Periodic Train Timetabling and Platforming Problems. EURO Journal of Transportation Logistics, 2015, vol. 4, no. 3, pp. 285320. DOI: $10.1007 / \mathrm{s} 13676-014-0046-4$

7. Bobrovsky V.I., Kozachenko D.N., Vernigora R.V., Malashkin V.V. Funktsional'noe modelirovanie raboty zheleznodorozhnoi stantsii [Functional Modeling of Railway Station Work], 2015, Dnepropetrovsk. (in Russian)

8. Bosov A.V., Ignatov A.N., Naumov A.V. Model of Transportation of Trains and Shunting Locomotives at a Railway Station for Evaluation and Analysis of SideCollusion Probability. Informatics and Applications, 2018, vol. 12, no. 3, pp. 107-114. DOI: $10.14357 / 19922264180315$ (in Russian)

9. Pravila tehnicheskoi ekspluatatsii zheleznyh dorog Rossiiskoi Federatsii $v$ redaktsii ot 05.10.2018 [Technical Operation Rules of the Russian Federation Railways from 05.10.2018]. Avalable at: http://docs.cntd.ru/document/902256286. (in Russian)

10. Famurewa S.M., Xin T., Rantatalo M., Kumar U. Optimisation of Maintenance Track Possession Time: a Tamping Case Study. Proceedings of the Institution of Mechanical Engineers. Part F: Journal of Rail and Rapid Transit, 2013, vol. 229, no. 1, pp. 12-22. DOI: $10.1177 / 0954409713495667$

11. Gustavsson E., Patriksson M., Stromberg A.-B. et al. Preventive Maintenance Scheduling of Multi-Component Systems with Interval Costs. Computers and Industrial Engineering, 2014, vol. 76, pp. 390-400. DOI: 10.1016/j.cie.2014.02.009

12. Andrade A., Teixeira P. Biobjective Optimization Model for Maintenance and Renewal Decisions Related to Rail Track Geometry. Transportation Research Record: Journal of the Transportation Research Board, 2011, vol. 2261, no. 1, pp. 163-170. DOI: 10.3141/2261-19

13. Higgins A. Scheduling of Railway Track Maintenance Activities and Crews. The Journal of the Operational Research Society, 1998, vol. 49, no. 10, pp. 1026-1033. DOI: 10.1057 /palgrave.jors.2600612

14. Albrecht A.R., Panton D.M., Lee D.H. Rescheduling Rail Networks with Maintenance Disruptions Using Problem Space Search. Computers and Operations Research, 2013, vol. 40, no. 3, pp. 703-712. DOI: $10.1016 /$ j.cor.2010.09.001

15. Forsgren M., Aronsson M., Gestrelius S. Maintaining Tracks and Traffic Flow at the Same Time. Journal of Rail Transport Planning and Management, 2013, vol. 3, no. 3, pp. 111-123. DOI: $10.1016 / \mathrm{j} . j \mathrm{rtpm} .2013 .11 .001$ 


\section{О ВЫБОРЕ ВРЕМЕНИ ДЛЯ УСТАНОВЛЕНИЯ «ТЕХНОЛОГИЧЕСКОГО ОКНА НА ЖЕЛЕЗНОДОРОЖНОЙ СТАНЦИИ}

\section{А.Н. Игнатов ${ }^{1}$, А.В. Наумов}

${ }^{1}$ Московский авиационный институт, г. Москва, Российская Федерация

Рассматривается задача по установлению «технологического окна»на железнодорожной станции - времени, в течение которого прекращается движение поездов по отдельным железнодорожным путям для производства ремонтно-строительных работ. Для этой цели на основе расписания движения по станции решаются задачи поиска максимального по длине промежутка времени, когда все участки пути, подлежащие ремонту, одновременно свободны. Кроме того, решается задача определения промежутка времени, длительности не меньше заданного, при котором занято минимальное число участков пути, подлежащих ремонту, а также промежутка времени, длительности не меньше заданного, при котором будет задержано или перенесено минимальное число пассажирских/грузовых поездов, следующих через участки пути, подлежащие ремонту. Все задачи решаются методами смешанного целочисленного линейного программирования.

Ключевые слова: «технологическое окно»; станиия; расписание; смешанное иелочисленное линейное программирование.

\section{Литература}

1. Cordeau, J.-F. A Survey of Optimization Models for Train Routing and Scheduling / J.-F. Cordeau, P. Toth, D. Vigo // Transportation Science. - 1998. - V. 32, № 4. P. 380-404.

2. Peeters, L.W.P. Cyclic Railway Timetable Optimization. PhD Thesis / L.W.P. Peeters. Rotterdam, 2003.

3. Azanov, V.M. Algorithm and Software Development to Allocate Locomotives for Transportation of Freight Trains / V.M. Azanov, M.V. Buyanov, D.N. Gaynanov, S.V. Ivanov // Вестник ЮУрГУ. Серия: Математическое моделирование и программирование. 2016. - T. 9, № 4. - C. 73-85.

4. Buyanov, M.V. Algorithm of Effective Transportation Work for Cargo Traffic / M.V. Buyanov, A.I. Kibzun // Вестник ЮУрГУ. Серия: Математическое моделирование и программирование. - 2018. - Т. 11, № 1. - С. 75-83.

5. Буянов, М.В. Развитие математической модели управления грузоперевозками на участке железнодорожной сети с учетом случайных факторов / М.В. Буянов, С.В. Иванов, А.И. Кибзун, А.В. Наумов // Информатика и ее применения. - 2017. - Т. 11, № 4. C. $85-93$.

6. Cacchiani, V. A Tutorial on Non-Periodic Train Timetabling and Platforming Problems / V. Cacchiani, L. Galli, P. Toth // EURO Journal of Transportation Logistics. - 2015. V. 4, № 3. - P. 285-320.

7. Бобровский, В.И. Функциональное моделирование работы железнодорожных станций / В.И. Бобровский, Д.Н. Козаченко, Р.В. Вернигора, В.В. Малашкин. - Днепропетровск: Днепропетровский национальный университет железнодорожного транспорта им. академика В. Лазаряна, 2015. 
8. Босов, А.В. Модель передвижения поездов и маневровых локомотивов на железнодорожной станции в приложении к оценке и анализу вероятности бокового столкновения / А.В. Босов, А.Н. Игнатов, А.В. Наумов // Информатика и ее применения. - 2018. T. 12, № 3. - C. 107-114.

9. Правила технической эксплуатации железных дорог Российской Федерации в редакции от 05.10.2018. - URL: http://docs.cntd.ru/document/902256286

10. Famurewa, S.M. Optimisation of Maintenance Track Possession Time: a Tamping Case Study / S.M. Famurewa, T. Xin, M. Rantatalo, U. Kumar // Proceedings of the Institution of Mechanical Engineers. Part F: Journal of Rail and Rapid Transit. - 2013. - V. 229, № 1. P. $12-22$.

11. Gustavsson, E. Preventive Maintenance Scheduling of Multi-Component Systems with Interval Costs / E. Gustavsson, M. Patriksson, A.-B. Stromberg et al. // Computers and Industrial Engineering. - 2014. - V. 76. - P. 390-400.

12. Andrade, A. Biobjective Optimization Model for Maintenance and Renewal Decisions Related to Rail Track Geometry / A. Andrade, P. Teixeira // Transportation Research Record: Journal of the Transportation Research Board. - 2011. - V. 2261, № 1. - P. 163-170.

13. Higgins, A. Scheduling of Railway Track Maintenance Activities and Crews / A. Higgins // Journal of the Operational Research Society. - 1998. - V. 49, № 10. - P. 1026-1033.

14. Albrecht, A.R. Rescheduling Rail Networks with Maintenance Disruptions Using Problem Space Search / A.R. Albrecht, D.M. Panton, D.H. Lee // Computers and Operations Research. - 2013. - V. 40, № 3. - P. 703-712.

15. Forsgren, M. Maintaining Tracks and Traffic Flow at the Same Time / M. Forsgren, M. Aronsson, S. Gestrelius // Journal of Rail Transport Planning and Management. - 2013. V. 3, № 3. - P. 111-123.

Алексей Николаевич Игнатов, кандидат физико-математических наук, кафедра «Теория вероятностей и компьютерное моделирование», Московский авиационный институт (г. Москва, Российская Федерация), alexei.ignatov1@gmail.com.

Андрей Викторович Наумов, доктор физико-математических наук, доцент, кафедра «Теория вероятностей и компьютерное моделирование», Московский авиационный институт (г. Москва, Российская Федерация), naumovav@mail.ru.

Поступила в редакиию 30 октября 2018 г. 